Revista Ciencia Multidisciplinaria CUNORI
http://revistacunori.com
DOI: https://doi.org/10.36314/cunori.v1i1.44
ISSN: 2617- 474X (impresa)/2617- 4758 (en línea)

\title{
La Muta de Oro y el Collar Chortí: Homenaje de máxima distinción otorgada al Centro Universitario de Oriente (CUNORI) por la trayectoria a favor de la sociedad chiquimulteca
}

\author{
La Muta de Oro and the Chortí Necklace: Tribute of maximum distinction awarded \\ to the University Center of the East (CUNORI) for the trajectory in favor of \\ Chiquimulteca society \\ Anibal Aroldo Guancín* \\ Centro Universitario de Oriente (CUNORI), Universidad de San Carlos de Guatemala \\ *Autor para correspondencia. \\ Correo electrónico: aroldoguancin@gmail.com
}

En el marco del 196 aniversario que la ciudad de Chiquimula fue elevada a la categoría de ciudad, el Concejo Municipal, en sesión celebrada el martes 20 de junio acordó entregar los galardones "Muta de Oro y el Collar Chortí", al Centro Universitario de Oriente, considerada como la más alta distinción que se otorga a personalidades o instituciones del municipio, por su contribución al desarrollo humano y la formación de valores cívicos y ciudadanos dentro de la sociedad.

El acto se llevó a cabo la tarde del 29 de junio de 2017, frente al Palacio Municipal, durante la ceremonia estuvieron presentes en representación del Rector de la Universidad de San Carlos de Guatemala el Dr. Carlos Camey Rodas, Secretario General de USAC, miembros del Consejo Directivo y el M. Sc. Nery Waldemar Galdámez Cabrera, Director de CUNORI, así como los miembros del Concejo Municipal, el Alcalde Rolando Arturo Aquino Guerra, alcaldes invitados, reinas de belleza e invitados especiales. 


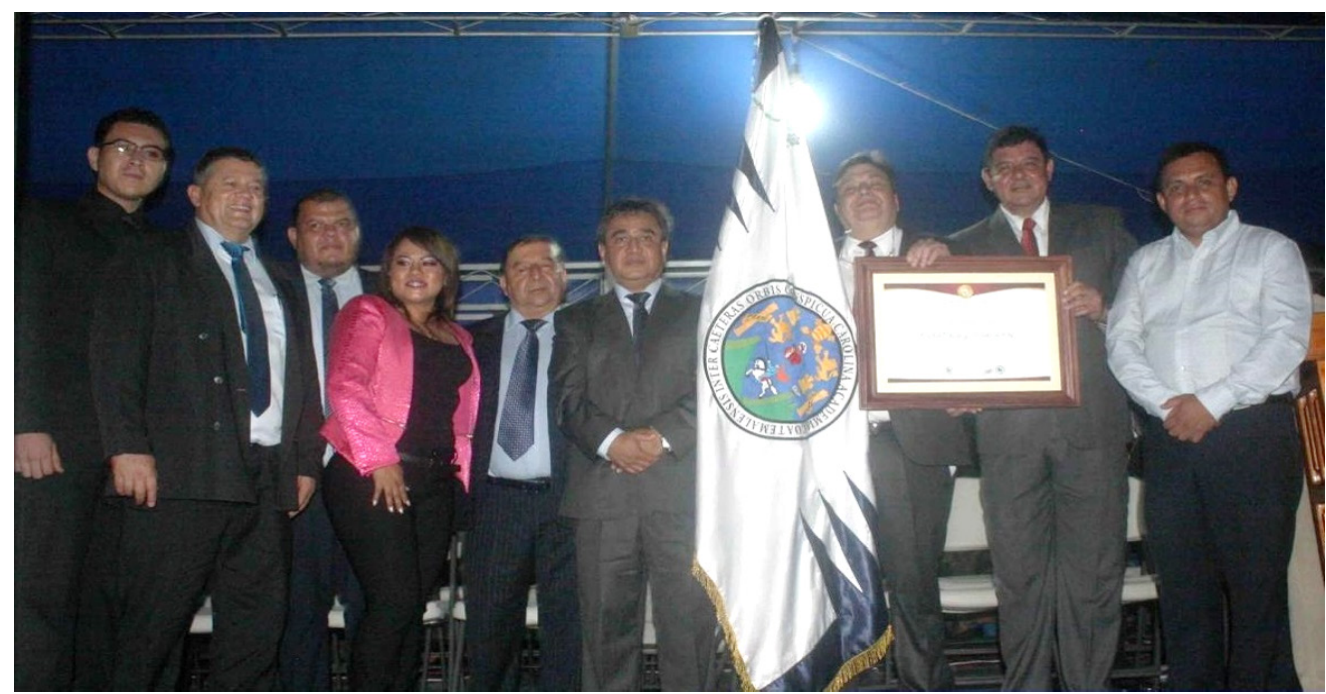

Fotografía: Comunicación y divulgación -CUNORI

Figura 1. Entrega de los galardones "Muta de Oro y el Collar Chortí”, al Centro Universitario de Oriente, recibido por las autoridades de Universidad de San Carlos de Guatemala y CUNORI.

\section{Sobre el autor}

\section{Anibal Aroldo Guancín}

Periodista. Licenciado en Ciencias de la Comunicación, Profesor Titular I, docente de los cursos Periodismo Radiofónico y Semiología del Mensaje Persuasivo en la Carrera de Ciencias de la Comunicación del Centro Universitario de Oriente, miembro de la comisión de Evaluación Privada de Periodista Profesional y miembro de la Cámara de Locutores Profesionales de Guatemala.

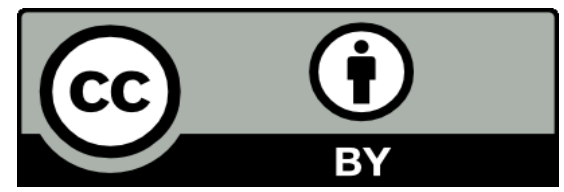

Este texto está protegido por una licencia CreativeCommons 4.0.

Usted es libre para compartir, copiar y redistribuir el material en cualquier medio o formato y adaptar el documento, remezclar, transformar y crear a partir del material para cualquier propósito, incluso comercialmente, siempre que cumpla la condición de atribución: usted debe reconocer el crédito de una obra de manera adecuada, proporcionar un enlace a la licencia, e indicar si se han realizado cambios. Puede hacerlo en cualquier forma razonable, pero no de forma tal que sugiera que tiene el apoyo del licenciante o lo recibe por el uso que hace. 